\title{
THE GUMMOSIS OF SUGAR CANE (Second Paper)
}

\author{
Mervilue T. CoOK \\ Plant Pathologist
}

The first paper on this subject by the writer was published in "The Journal of the Department of Agriculture of Porto Rico", Vol. XII, No. 3, October 1928. At that time, it was our intention to continue the work for two or possibly three years longer, to make a second test of our established varieties and to test several newly introduced and promising varieties. But when our plots were harissted on March 14th and 15th, 1929, it was found that we did not have enough diseased seed cuttings for the establishment of new plots. Therefore, it was impossible to continue the work and became necessary to publish this brief resume of the work to date. Those who are interested in this work should read the first paper.

The conditions for the growing of this third crop (2nd ratoon) have been very unfavorable. Following the cutting of the second crop (1st ratoon) in February 1928, we had dry weather. The weather conditions and the disease caused a growth that was very much less than the cane surrounding the plots. This reduced growth must be attributed primarily to the presence of the disease. This cane was in the path of the September 13th eyclone and was severely damaged. The cane was so poor as to be scarcely worth eutting if it had not been for our desire to make records of the amount of infection. The cane surrounding these experimental plots and separated Hom them by a wagon road only was up to the average.

A summarization of the amount of infection is as follows:

(1) Cristalina, which was planted from diseased seed in 1925 showed an average of less than one per cent infection. Eighteen rows of 45 stools each showed no infection. Twelve rows showed slight infection. The highest infection in any row was less than 4 per cent. The infection in 1927 was 85 per cent and in 1928 varied from less than 10 per cent in some rows to 50 per cent in other rows.

(2) PR-292, PR-492 and D-433 showed less than one per cent infection. They did not show any infection in 1928 but the number of living stools had been reduced in every case.

(3) Ba-11569 showed less than one per cent infection. In 1928 this variety showed 7.1 per cent infection and a loss of 3 stools out of 45 . 
(4) X-62 showed about two per cent infection. In 1928 this variety showed 7.7 per cent infection and a loss of 19 stools out of 45 .

(5) B-3412 showed about two per cent infection. In 1928 this variety did not show any infection but there had been a loss of 5 stools out of 45 .

(6) E.K.-28 showed five per cent infection. In 1928 this variety showed 50 per cent infection.

(7) D-504 showed about 17 per cent infection. In 1928 this variety showed an infection of 12.5 per cent and a loss of 8 out of 15 stools.

(8) Otaheiti showed but one living stool out of 45 stools planted in 1925. This stool had but two canes and both were infected.

(9) B-3405, B-6032, H-109, PR-219, PR-260, PR-328, PR-487, and PR-460 showed more or less infection in 1928 but no infection in 1929.

(10) The following varieties did not show any infection on either first (1928) or second (1929) ratoon: St. Kitts, Yellow Caledonia, Badila, GC-493, FC-214, SC-12(4), BH-10(12), D-109, D-117, D-1135, B-208, B-1753, B-1809, B-3696, B-6032, B-6308, PR-67, PR-202, PR-230, PR-329, PR-333, PR-358, PR-417 and PR-729.

(11) The following varieties did not show any infection on either the plant cane (1927) or the two ratoons (1928 and 1929): D-448, PR-318, POJ-228, POJ-234, POJ-826, POJ-979, M-36 and Uba.

In 1928 small plantings of several varieties were made and the results may be summarized as follows: BSF-1248, BH-10(12), Sealey seedling, Tuc-439, B-119, B-12079, PR-422, PR-430, PR-433, PR502, PR-503, PR-545, PR-676, POJ-36, POJ-503, PR-1228, POJ2725 and POJ-2776 which did not show any infection. D-357 showed one per cent infection and SC-12(4) showed five per cent.

The studies on this disease in Porto Rico and elsewhere present two very interesting questions. (1) Why does the disease appear suddenly in abundance? and (2) Why is the infection greater in plant than in ratoon cane?

Two and possibly more answers may be given to the first question. (a) The grower may unknowingly have planted infected seed. The disease may have been present on a property in small infections for some time. Finally the grower may have used a large amount of seed from an infected area and the conditions may have been favorable for the development of the disease. The result is a large amount of disease in the crop.

The second question may possibly be explained as follows: A 
large percentage of the shoots from an infected seed piece are likely to show infection which means a high percentage of infection in the crop as has been demonstrated by some of our experiments. The infection exists not only above the ground but also in the underground parts of the stems or rhizomes. In severely infected stools some of these underground parts are killed which results in a reduced tonnage in the crop. After the cutting of the first crop many of the new shoots are killed as shown in our experiments. The mortality among the small shoots is very high but shoots of five feet feet or more in height are sometimes killed. Shoots that are only slightly infected or that may escape infection entirely will survive but the tonnage of the ratoon crop is necessarily reduced in proportion to the death of the underground parts and new shoots. Since the surviving shoots are those that were healthy or only slightly infected the percentage of infection will be lower in the first ratoon than in the plant crop and lower in the second than in the first ratoon.

\section{DISCUSSION}

It appears from these studies that the planting of infected cane will give losses in first erop in proportion to the amount of infection * in the seed, the relative resistance of the variety and the weather conditions during the growing season. Severely infected seed pieces may not germinate but very few such pieces will be used. Many of the new shoots from infected cuttings will die as a result of the disease which will reduce the crop. However, many slightly infected shoots will survive and the percentage of disease in the first crop or plant cane will be high.

In the production of the second erop (1st ratoon) many of the underground parts will die as a result of the disease. Many of the new shoots will die and others will be weak for lack of necessary plant food. The percentage of young shoots which die during the second year appears to be greater than during the first year. Therefore, the percentage of living infected shoots at cutting time is less than when the first crop is cut but the tomnage is also redueed as a result of the death of so many shoots.

Likewise the third crop (2nd ratoon), for the same reasons will show a still lower percentage of infection and a still lower tonnage. Of course both the percentage of infection and the amount of the tonnage may vary to some extent with the soil and weather conditions.

Under present conditions in Porto Rico, our two favorite eanes, $\mathrm{BH}-10(12)$ and $\mathrm{SC}-12(4)$ can be grown with very little fear of losses 
from gummosis, but the grower should never use seed cuttings from an infected field.

High producing susceptible varieties of sugar cane can be grown in territory where the disease is not present but in case the disease appears in these localities the growers should replant the infected fields with highly resistant varieties. The POJ eanes which we have tested in Porto Rico appear to be immune to the clisease.

The abandoning of the old favorites such as Cristalina, Rayada, Otaheiti and Yellow Caledonia, the inereased planting of BH-10(12), SC-12(4), Uba and the POJs, leads the writer to believe that the gummosis disease is a diminishing factor in Porto Rico. However, any disease is a menace to the crop on which it exists, because a change in conditions may enable it to become a dangerous factor. So long as this disease exists on the island, it will be a dangerous factor in the development of or introduction of a new desirable but susceptible variety.

$$
0-0-0
$$

